\title{
Inverted migration of rare whisker sheatfish in Nong-Han Lake, northeastern Thailand: Implications for conservation
}

\author{
P. Phongkaew ${ }^{1,2}$, U. Arunyawat ${ }^{1}$, A. Swatdipong ${ }^{1}$ and V. Hongtrakul ${ }^{1,3}$ \\ ${ }^{1}$ Department of Genetics, Faculty of Science, Kasetsart University, \\ Bangkok, Thailand \\ ${ }^{2}$ Faculty of Natural Resources and Agro-Industry, Kasetsart University, \\ Sakon Nakhon, Thailand \\ ${ }^{3}$ Center for Advanced Studies in Tropical Natural Resources, \\ National Research University-Kasetsart University, Chatuchak, Bangkok, Thailand \\ Corresponding author: V. Hongtrakul \\ E-mail: fscivph@ku.ac.th
}

Genet. Mol. Res. 13 (3): 7492-7502 (2014)

Received July 24, 2013

Accepted November 18, 2013

Published September 12, 2014

DOI http://dx.doi.org/10.4238/2014.September.12.16

\begin{abstract}
Nong-Han Lake, Thailand, sustains the whisker sheatfish (Micronema bleekeri Günther, 1864), which is a rare species of freshwater catfish. Wild-caught whisker sheatfish has been intensively harvested to meet market demand; yet, genetic information about this species remains unknown. To assist with the in situ conservation of whisker sheatfish populations in Nong-Han Lake, 35 and 34 individuals from the middle (MN) and lower (LN) areas of the lake, respectively, were studied using 7 microsatellite loci. Low genetic variation was detected in the $\mathrm{MN}\left(H_{\mathrm{O}}=0.338, A_{\mathrm{R}}=2.710\right)$ and $\mathrm{LN}\left(H_{\mathrm{O}}=0.394, A_{\mathrm{R}}=\right.$ 2.714) populations. Genetic differentiation between the 2 populations was significant $\left(F_{\mathrm{ST}}=0.063, \mathrm{P}<0.05\right)$. The size of recent populations $\left(N_{\mathrm{E}}<50\right)$ was found to be 9- to 29-times smaller compared to the estimated historical populations, even though no bottleneck signal was observed. Low genetic diversity was observed, implying that the
\end{abstract}


populations are at risk of being lost from this site. Of note, migration among the populations inhabiting the middle and lower parts of the lake exhibited opposing trends in changes to the genetic structure. This phenomenon might be due to the operation of a regional irrigation gate over the last decade. The information collected here indicates that the whisker sheatfish populations in Nong-Han Lake require consistent fisheries monitoring and management. Further research about the whisker sheatfish populations from the Mekong and Chao Phraya River basins is required to assist national-scale conservation efforts.

Key words: Effective population size; Microsatellite; Migration; Nong-Han Lake; Whisker sheatfish

\section{INTRODUCTION}

The whisker sheatfish (Micronema bleekeri Günther, 1864) is a rare freshwater catfish. The meat of this species is appreciated by local people, making it an economically important fisheries resource. In Thailand, the whisker sheatfish occupies a wide variety of habitats, including rivers, tributaries, floodplains, and swamps. This species is almost completely harvested from natural sources; however, attempts to develop aquaculture programs have been made to meet the high market demand for this species, but with limited success. Consequently, whisker sheatfish populations have been subject to an inevitable decline, primarily caused by over-fishing, habitat degradation, and reduced natural habitat water levels due to high water use for agricultural irrigation. Moreover, this species was recorded as rare at this site in the report of the Sakon Nakhon Inland Fisheries Research and Development Center (Ngoichansri et al., 2002; Daungsawat et al., 2003).

Nong-Han Lake $\left(17^{\circ} 06^{\prime}-17^{\circ} 15^{\prime} \mathrm{N}, 104^{\circ} 07^{\prime}-104^{\circ} 20^{\prime} \mathrm{E}\right)$ is the largest inland water resource of northeastern Thailand. This lake has a high diversity of freshwater fish species, with at least 44 species of fish being taxonomically recorded to date (Jintanugool and Round, 2011). Nong-Han Lake is also one of the sites that have been selected for the implementation of the Large Swamp Inland Fisheries Project, which aims to increase fish productivity through intensive stocking. The major outflow of the lake enters the Nam Kum basin, which further drains southeast to the world's great Mekong River. The water level of Nong-Han Lake is regulated by the Nam Kum Gate, which is composed of 1 spillway and 2 sluice gates that have been operated for over 15 years. The average depth of the lake is $1.9 \mathrm{~m}$, with a maximum depth of $4.3 \mathrm{~m}$. The water level of Nong-Han Lake fluctuates considerably. At the peak of summer, some marginal areas are completely dry, while other areas are very shallow; thus, creating geographical barriers among fish populations (Jintanugool and Round, 2011).

Microsatellites represent a well-known DNA marker. A microsatellite consists of simple sequences of a unit with 1-6 bases that may be iterated to lengths of up to 100 base pairs (Ellegren, 2004). Changes in the length of microsatellite DNA are generally thought to arise from slippage during the replication process, leading to insertions or deletions of repeat units relative to the template strand (O'Connell and Wright, 1997). Replication slippage also occurs during the polymerase chain reaction amplification of microsatellite sequences in vitro. This type of marker represents a promising tool for a wide range of genetic studies, including genetic linkage map- 
ping, conservation genetics, aquaculture, and population genetics (Quan et al., 2006). Microsatellite markers have advantages over other molecular markers because of their locus-specific and co-dominant characteristics. These markers are generally assumed to evolve neutrally (Ellegren, 2004), to be highly polymorphic, and to be widely distributed throughout the fish genome. Only small amounts of DNA are required for microsatellite amplification using PCR and, importantly, the genotypes of microsatellites are highly reproducible (O'Connell and Wright, 1997). Microsatellites have been successfully used to estimate genetic variation in wild and hatchery stocks of many fish species (Hogan and May, 2002; Na-Nakorn et al., 2006; So et al., 2006). In Thailand, several freshwater catfish species have been subject to genetic and population structure studies, including the walking catfish (Na-Nakorn et al., 2004), the striped catfish (Na-Nakorn and Moeikum, 2009), and the giant catfish (Na-Nakorn et al., 2006; Ngamsiri et al., 2006); however, such studies have not been conducted on wild populations of whisker sheatfish. Knowledge about the genetic variation and population characteristics of the whisker sheatfish is thus currently unavailable; yet, it is important to obtain genetic information about this species to assist effective fishery management programs and to safeguard the genetic diversity of the species.

This study aimed to investigate the genetic diversity and population characteristics of the whisker sheatfish in Nong-Han Lake, northeastern Thailand.

\section{MATERIAL AND METHODS}

\section{Sample collection and DNA extraction}

Thirty-five and 34 whisker sheatfish specimens were collected from the middle (MN) and lower (LN) areas of Nong-Han Lake, Sakon Nakhon Province, Thailand during OctoberDecember, 2008. The collection sites were based on Ngoichansri et al. (2002) (Figure 1). Information about sample collection is presented in Table 1. Species identification was based on Rainboth (1996). Tissue samples (about $10 \mathrm{mg}$ ) were collected from the distal part of the caudal fin of each fish specimen, and were then preserved in absolute ethanol until DNA extraction. DNA was extracted from samples using an Aqua Pure Genomic DNA Isolation kit (Bio-Rad, California, USA), and analyzed by gel electrophoresis on $1.0 \%$ agarose gel stained with ethidium bromide, and compared with the Gene Ruler ${ }^{\mathrm{TM}}$ DNA ladder mix (Fermentas, Vilnius, Lithuania).

\section{Microsatellite genotyping}

The whisker sheatfish samples were genotyped at 7 microsatellite loci (MB79, MB81, MB153, MB320, MB401, MB456, and MB645), as described by Phongkaew et al. (2011). PCR reactions were carried out in $12.5 \mu \mathrm{l}$ volumes containing $50 \mathrm{ng}$ of genomic DNA, $20 \mathrm{mM}$ Tris- $\mathrm{HCl}, \mathrm{pH} 8.4,50 \mathrm{mM} \mathrm{KCl}, 1.5 \mathrm{mM} \mathrm{MgCl}_{2}, 2.0 \mathrm{mM}$ dNTP, 2 pmol of each primer, and $1 \mathrm{U}$ Taq DNA polymerase (Invitrogen, Oslo, Norway) on an XP cycler (BIOER, Hangzhou, China). The thermal profile for all loci involved initial denaturation at $94^{\circ} \mathrm{C}$ for $5 \mathrm{~min}$, followed by 35 cycles at $94^{\circ} \mathrm{C}$ for $45 \mathrm{~s}$, annealing at $53^{\circ} \mathrm{C}-61^{\circ} \mathrm{C}$ for $30-45 \mathrm{~s}$ (depending on the locus), and at $72^{\circ} \mathrm{C}$ for $30-45 \mathrm{~s}$, and a final extension at $72^{\circ} \mathrm{C}$ for $5 \mathrm{~min}$. The PCR products were subsequently separated on $6 \%(\mathrm{w} / \mathrm{v})$ denaturing polyacrylamide gel (Bio-Rad, California, USA), and visualized after silver-staining. The alleles were sized based on the $50 \mathrm{bp}$ standard marker (Fermentas). 


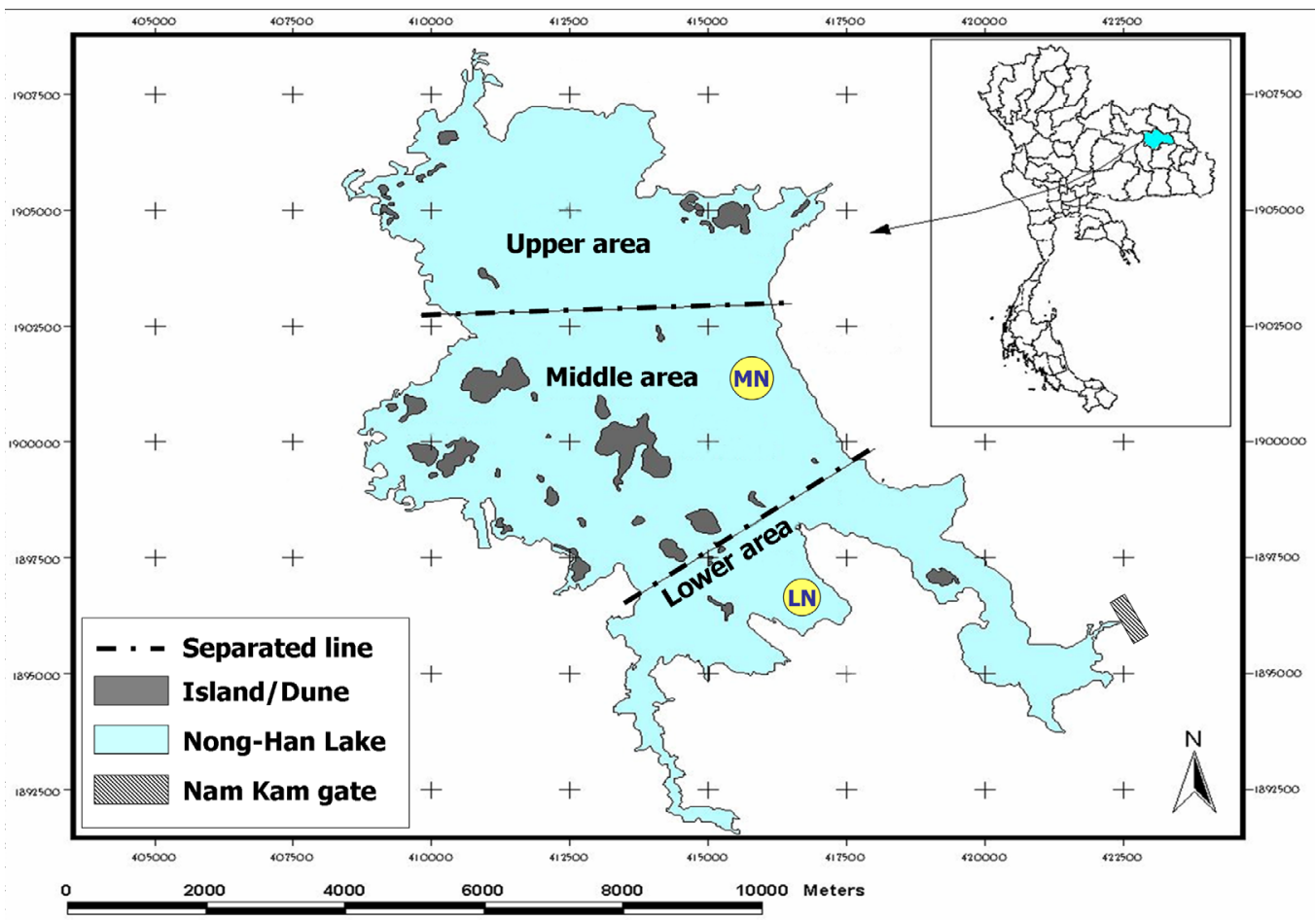

Figure 1. Collection sites of whisker sheatfish samples in the Nong-Han Lake, Sakon Nakhon Province, Thailand. Middle area $(\mathrm{MN})\left(17^{\circ} 11^{\prime} 20.05^{\prime \prime} \mathrm{N}, 104^{\circ} 12^{\prime} 46.19^{\prime \prime} \mathrm{E}\right)$ and lower area (LN) (17 09'26.92"N, 104 $\left.12^{\prime} 37.20^{\prime \prime} \mathrm{E}\right)$. Map re-drawn from Ngoichansri et al. (2002).

Table 1. Summary of genetic variability across microsatellite loci of whisker sheatfish populations in the middle (MN) and lower (LN) area populations of Nong-Han Lake.

\begin{tabular}{|c|c|c|c|c|c|c|c|c|c|}
\hline \multirow[t]{2}{*}{ Collection site } & \multirow[t]{2}{*}{ Latitude/ Longitude } & \multirow{2}{*}{$\begin{array}{c}\text { Sampling } \\
\text { year }\end{array}$} & \multirow{2}{*}{$\begin{array}{l}\text { Number of } \\
\text { samples }\end{array}$} & \multicolumn{6}{|c|}{ Microsatellite diversity } \\
\hline & & & & $A$ & $A_{\mathrm{E}}$ & $A_{\mathrm{R}}$ & $H_{\mathrm{o}}$ & $H_{\mathrm{E}}$ & $F_{\text {IS }}$ \\
\hline Middle area of Nong-Han Lake (MN) & $\begin{array}{r}17^{\circ} 11^{\prime} 20.05^{\prime \prime N} \\
104^{\circ} 12^{\prime} 46.19^{\prime \prime E}\end{array}$ & 2008 & 35 & 2.714 & 1.762 & 2.710 & 0.338 & 0.360 & 0.060 \\
\hline Lower area of Nong-Han Lake (LN) & $\begin{array}{c}17^{\circ} 09^{\prime} 26.92^{\prime \prime N} \\
104^{\circ} 12^{\prime} 37.20^{\prime \prime} \mathrm{E}\end{array}$ & 2008 & 34 & 2.714 & 1.871 & 2.714 & 0.394 & 0.424 & 0.071 \\
\hline Mean & & & & 2.714 & 1.816 & 2.712 & 0.366 & 0.392 & 0.065 \\
\hline
\end{tabular}

$A=$ Number of alleles per locus; $A_{\mathrm{E}}=$ effective number of alleles per locus; $A_{\mathrm{R}}=$ allelic richness; $H_{\mathrm{O}}=$ observed and $H_{\mathrm{E}}=$ expected heterozygosity; $F_{\mathrm{IS}}=$ degree of inbreeding.

\section{Statistical analyses}

\section{Microsatellite diversity, Hardy-Weinberg, and linkage disequilibrium}

Evidence for genotyping error and large allele dropout for each locus within each 
population was assessed using MICRO-CHECKER 2.2.3 (van Oosterhout et al., 2004). Genotype data of whisker sheatfish from 7 microsatellite loci were used to calculate the effective number of alleles $\left(N_{E}\right)$, observed heterozygosity $\left(H_{\mathrm{O}}\right)$, and expected heterozygosity $\left(H_{\mathrm{E}}\right)$ by the POPGEN 32 software package (Yeh and Yang, 1999). Allelic richness $\left(A_{\mathrm{R}}\right)$ was calculated using FSTAT 2.9.3.2 (Goudet, 2001). Deviations from Hardy-Weinberg and linkage equilibrium between pairs of loci were tested using Genepop 3.4 (Raymond and Rousset, 1995). Sequential Bonferroni correction (Holm, 1979) was employed to account for multiple testing.

\section{Genetic differentiation within and between populations}

To evaluate the extent of differentiation, the degree of inbreeding among individuals relative to the rest of their sub-population was calculated for loci based on $F_{\text {IS }}$, while interpopulation differentiation was calculated based on the multilocus $F_{\mathrm{ST}}$ estimator of Weir and Cockerham (1984) using FSTAT 2.9.3.2 (Goudet, 2001).

\section{Estimation of effective population size and migration rate}

The maximum likelihood-based (ML) coalescent Markov Chain Monte Carlo (MCMC) approach was used to infer the long term (i.e., 'historical') effective population size, $\theta\left(\theta=4 N_{\mathrm{e}} \mu\right.$; where $N_{\mathrm{e}}$ is the effective population size; $\mu$ is the mutation rate per site) and the historical migration pattern, $M(M=\mathrm{m} / \mu$; where $\mathrm{m}$ is the immigration rate per generation) among whisker sheatfish populations using the program MIGRATE 3.2.6 (Beerli, 2008). For each locus in the dataset, the ML was run for 10 short and 1 long chains, with 50,000 and 500,000 recorded genealogies, respectively, after discarding the first 10,000 genealogies (burn-in) for each chain. SVAR 1.3 (Beaumont, 2004) was used to predict the mutation rate of whisker sheatfish that is currently unknown, but required for the calculation of $\mathrm{m}$ (from $M \mu$ in MIGRATE 3.2.6). MSVAR simulations were run for $2 \times 10^{8}$ iterations, and the first $10 \%$ of the output was discarded as the burn-in period. Hence, the remaining output was used to estimate the mutation rate of whisker sheatfish.

The 'recent' effective population size was assessed from a temporal sample using an approximate Bayesian computation approach implemented in the program ONeSAMP 1.2 (Tallmon et al., 2008). Prior lower and upper bounds of $N_{\mathrm{E}}$ were set at 2 and 1000, respectively, based on a preliminary survey using the linkage disequilibrium method (Hill, 1981) implemented in NeEstimator 1.3 (Peel et al., 2004).

To estimate recent migration and its direction, a Bayesian method based on multilocus genotypes implemented in BAYESASS was used (Wilson and Rannala, 2003). It is assumed that the loci in the source population were in linkage equilibrium. The method to estimate the posterior probabilities of the migration matrix among neighboring populations is based on MCMC.

\section{Population bottleneck}

Potential demographic changes or substantial reduction in population size might cause bottleneck effects on the populations of this species. To detect any substantial reduction in population size that commonly occurs in populations of highly exploited species, genetic signatures of the reduction was investigated using the $M$ ratio (Garza and Williamson, 2001), Wilcoxon's 
sign-rank test (Luikart et al., 1998a), and mode-shift test (Luikart et al., 1998b). $M$ statistic values were calculated by $M=k / r$, which simply measures the ratio of the number of alleles, $k$, to the range in allele size, $r$, across microsatellite loci. In addition, the Wilcoxon's sign-rank test (Luikart et al., 1998a) and a mode-shift indicator test (Luikart et al., 1998b) were performed using BOTTLENECK 1.2.02 (Piry et al., 1999). In the Wilcoxon's sign-rank test, simulations were completed with $95 \%$ confidence intervals (re-sampling for 10,000 replications). The heterozygosity that was expected in a population at mutation drift equilibrium, $H_{\mathrm{eq}}$, was calculated under both a strict single step mutation model (SMM) and a realistic (Di Rienzo et al., 1994) two-phase mutation model (TPM), that included a 95\% SMM and 5\% multistep mutations model (IAM), with $12 \%$ variance in TPM being employed, following the recommendation of Piry et al. (1999).

\section{RESULTS}

\section{Genetic diversity and genetic differentiation of whisker sheatfish}

In total, 38 alleles were observed from the 2 sheatfish populations genotyped at 7 microsatellite loci. The number of alleles per locus ranged from 2 to 4 . There were no null alleles, nor were any other genotyping errors detected among loci. No Hardy-Weinberg deviation and no linkage disequilibrium were found in the 2 populations after sequential Bonferroni correction $(\mathrm{P}>0.007)$. For the $\mathrm{MN}$ population, the observed heterozygosity $\left(H_{\mathrm{O}}\right)$ was 0.338 and the expected heterozygosity $\left(H_{\mathrm{E}}\right)$ was 0.360 . For the LN population, the $H_{\mathrm{O}}$ was 0.394 and the $H_{\mathrm{E}}$ was 0.424 . The inbreeding coefficient of both the $\mathrm{MN}$ and $\mathrm{LN}$ populations was observed across loci (MN: $F_{\text {IS }}=0.060,95 \%$ confidence limits $-0.181-0.285 ; \mathrm{LN}: F_{\text {IS }}=0.071,95 \%$ confidence limits -0.103-0.448). Means of allelic richness $\left(A_{\mathrm{R}}\right)$ were 2.710 and 2.714 for the $\mathrm{MN}$ and LN populations, respectively. A summary of genetic variability across microsatellite loci is shown in Table 1 and Table S1. The estimate of $F_{\mathrm{ST}}$ between the 2 whisker sheatfish populations was significant with moderate genetic differentiation $\left(F_{\mathrm{ST}}=0.063, \mathrm{P}<0.05\right)$.

\section{Population bottleneck observation}

As the whisker sheatfish is considered to be a rare, but exploited species, it is likely that there has been a reduction in population size. The $M$ ratio across loci was 1 (no bottleneck signal) for both MN and LN populations. Under strict SMM and TPM (95\% SMM and 5\% IAM), the Wilcoxon's sign-rank test did not reveal any recent bottleneck signal in whisker sheatfish populations. The mode-shift test on allele frequency distributions did not display any evidence of bottlenecks.

\section{Effective population size and migration rate: historical versus recent}

The maximum likelihood-based coalescent Markov Chain Monte Carlo (MCMC) approach inferred that the mutation scaled population size parameter was higher in the LN population $(\theta=0.510)$ compared to the MN population $(\theta=0.401)$. Between the 2 populations, the mutation rate across loci was similar, at 2.7-2.8 $\times 10^{-4}$ per generation. These estimates were translated to a historical effective population size $\left(N_{\mathrm{E}}\right)$ of 358 and 462 in the $\mathrm{MN}$ and $\mathrm{LN}$ populations, respectively (Figure 2). 

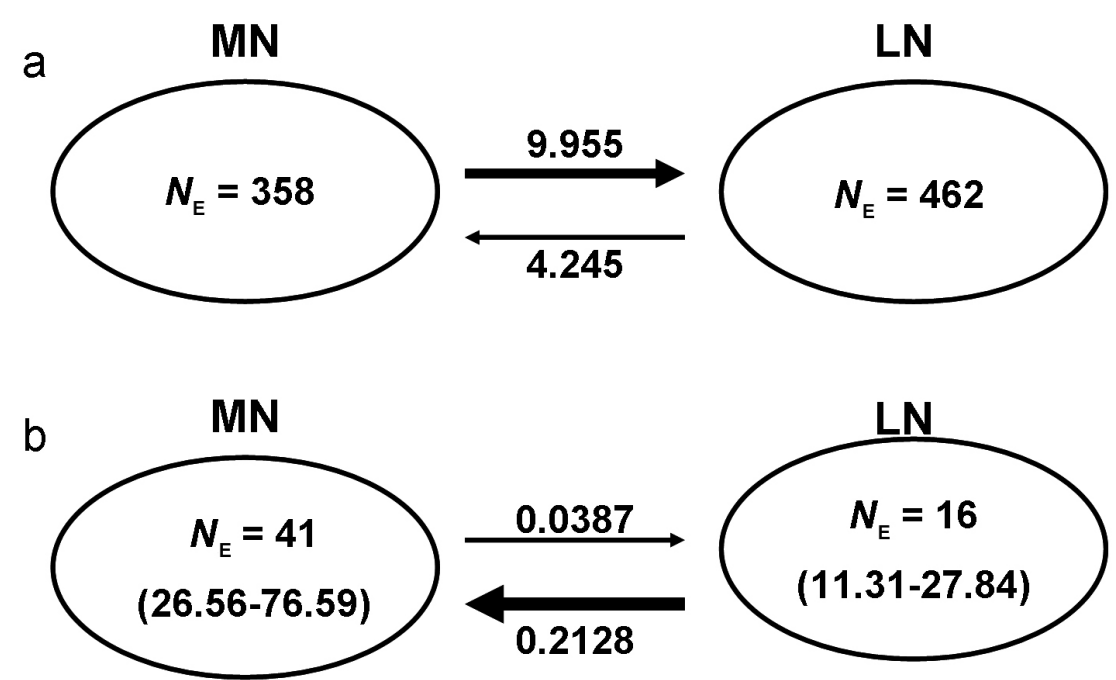

Figure 2. A. Estimates of the effective historical population size $(\theta)$, gene flow and migration directions (numbers and arrows) for middle area (MN) and lower area ( $\mathrm{LN})$ populations of whisker sheatfish estimated in MIGRATE (Beerli, 2008); B. Estimates of recent effective population size $\left(N_{\mathrm{E}}\right)$ using linkage disequilibrium (Tallmon et al., 2008) and migration rate and directions for MN and LN populations of whisker sheatfish estimated in BAYESASS (Wilson and Rannala, 2003).

The estimated recent effective population size using the approximate Bayesian computation method for the MN population was 41 (95\% confidence interval: 26.56-76.59), whereas it was 16 (95\% confidence interval: 11.31-27.84) for the LN population (Figure 2).

Using the maximum-likelihood approach, the historical migration rate of the MN to the LN population was 9.955, while movement in the opposite direction was 4.245 . In contrast, the Bayesian method revealed a reduction in recent migration rates. The recent migration rate of the MN population to the LN population was 0.0387 , which was 257 times lower compared to the historical migration rate. The recent migration rate of the LN population to the MN population was 0.2128 , which was 19 times lower compared to the historical migration rate (Figure 2).

\section{DISCUSSION}

Whisker sheatfish is considered a rare species, with low genetic diversity being expected. In our study, 2 populations of whisker sheatfish in Nong-Han Lake exhibited low allele numbers (average $A_{\mathrm{R}}=2.714$ ), in addition to low observed and expected heterozygosity (average $H_{\mathrm{O}}=$ $0.366 ; H_{\mathrm{E}}=0.392$ ), when compared to populations of other freshwater fishes described by De Woody and Avise (2000). When using 75 microsatellite loci, the authors obtained an average $A$ and $H_{0}$ of $9.1 \pm 6.1$ and $0.54 \pm 0.25$, respectively, for 13 species of freshwater fish. Moreover, So et al. (2006) obtained an average allelic richness of 9.9 for the migratory sutchi catfish. In addition, Na-Nakorn and Moeikum (2009) reported an allelic richness of 5.6 across the loci of striped catfish in Vietnam. Foulley and Ollivier (2006) suggested that allelic richness is particularly important over the long-term, because it better reflects past fluctuations in population size. In terms 
of heterozygosity, Quan et al. (2006) obtained an average $H_{\mathrm{O}}$ and $H_{\mathrm{E}}$ of 0.43 and 0.75 , respectively, for 22 wild individuals of northern sheatfish (Silurus soldatovi). Surprisingly, the genetic diversity of whisker sheatfish was lower compared to the critically endangered Mekong giant catfish, Pangasainodon gigas, observed by Na-Nakorn et al. (2006) and Ngamsiri et al. (2006). These authors obtained averages of 0.55 and 0.37 for $H_{\mathrm{O}}$ and 0.49 and 0.44 for $H_{\mathrm{E}}$, respectively, for these 2 critically endangered species. In addition, the overall $F_{\text {IS }}$ value among all loci of the whisker sheatfish was higher than zero, indicating a certain level of heterozygote deficit. This heterozygote deficiency might also be explained by selection, inbreeding, population substructure, and null alleles (Crow and Kimura, 1970). Because of small population size or small numbers of families, the positive $F_{\text {IS }}$ value indicated that inbreeding was one of the main causes for the shortage of heterozygotes in the whisker sheatfish population. This suggestion was concordant with many existing reports about other freshwater fishes. For instance, So et al. (2006) found a significant $F_{\text {IS }}$ value (0.028) at a spawning area of migratory sutchi catfish. Parra-Bracamonte et al. (2011) found that the degree of inbreeding increased from 0.23 to 0.27 over a 4-year period in a traditional catfish hatchery channel. In this study, we found that the whisker sheatfish in NongHan Lake had low genetic diversity, and had a high tendency of inbreeding.

Whisker sheatfish undertake lateral migrations. For example, the geography, landscape, water level of the water body, and the structures that are built to impound water might affect gene flow (Hanfling and Weetman, 2006). There are no previous reports about the movement pattern of whisker sheatfish populations within Nong Han Lake and between other watercourses. However, the lack of fish movement barriers in the past allowed whisker sheatfish populations in Nong-Han Lake to freely migrate to Nam Kum basin, and finally to the Mekong River. In our results, major historical migrations occurred from $\mathrm{MN}$ to $\mathrm{LN}$ populations $\left(\mathrm{m}_{\mathrm{MN} \rightarrow \mathrm{LN}}=9.955 ; \mathrm{m}_{\mathrm{L}}\right.$ ${ }_{\mathrm{N} \rightarrow \mathrm{MN}}=4.245$ ). This result implied that gene flow among whisker sheatfish populations in NongHan Lake naturally moves southwards, which is the migratory route to the outlet of Nong-Han Lake leading to Nam Kum Basin and the Mekong River. Today, the migratory route from NongHan Lake to the Mekong River is obstructed by the Nam Kum gate (Jintanugool and Round, 2011), which only opened during the flood season (June to September). From year to year, environmental characteristics might change and influence migratory route or direction (Bunt, 2001). Therefore, whisker sheatfish were prevented from moving to areas downstream of the lake. The LN whisker sheatfish population has limited opportunities for downstream migration, resulting in it migrating in the opposite direction, i.e., upstream. The migration pattern showed that the recent migration rate from the $\mathrm{LN}$ to the $\mathrm{MN}$ population was more than 5 times greater compared to the opposite direction. During sample collection, it was observed that whisker sheatfish in Nong-Han Lake only moved between the lower and middle areas of the lake, and did not enter the upper area. The LN population was more influenced by the sluice gates compared to the MN population. Thus, the $\mathrm{LN}$ population of whisker sheatfish attempted to migrate back to the middle area of the lake, rather than migrating to the Nam Kum gate. This observation indicates that an anthropogenic barrier might dramatically alter migratory behavior, and cause a clear inversion in the direction of gene flow among populations of whisker sheatfish in Nong-Han Lake, as reported for other species of Cottus gobio (Hanfling and Weetman, 2006).

When the population size is small, as in the study populations, bottleneck signatures are expected. However, in our study, evidence of a recent genetic bottleneck was indicated by 3 different statistical methods. Hundertmark and van Daele (2010) suggested that populations with low levels of diversity might have undergone a bottleneck within a short period of time, and that 
such populations might recover following a process described by Garza and Williamson (2001). The authors showed that, for a small population, $M$ continues to decline for approximately 50 generations before it begins to recover. However, the authors also found that even when the value of $M$ has partially recovered, allelic diversity does not recover in a small population. In addition, a significant reduction in whisker sheatfish population size was observed based on estimates of effective population size. The current study showed that whisker sheatfish populations had small historical effective population size $(\mathrm{MN}=358 ; \mathrm{LN}=462)$, whereas the recent population size was reduced ( $\mathrm{MN}=41 ; \mathrm{LN}=16)$. In general, a population of $N_{\mathrm{E}}=500$ is considered to be large enough to maintain genetic diversity for key life-history traits; hence, genetic diversity would only appear to be depleted if $N_{\mathrm{E}}<500$ (Frankham, 1995). In addition, Franklin (1980) found that inbreeding depression is prevented when $N_{\mathrm{E}}>50$, whereas the viability or reproductive fitness of a population will decrease when $N_{\mathrm{E}}<50$. Therefore, at present, the whisker sheatfish population in Nong-Han Lake is vulnerable and at risk of population extinction within short period of time.

Various management strategies should be implemented to safeguard the rare whisker sheatfish populations of Nong-Han Lake, which have been subject to a genetic bottleneck and migratory obstruction. First, lake restoration should be conducted; for example, the gate should be opened for suitable time periods at times of the year relevant to the reproductive strategies of this fish population. Second, fish sanctuaries should be created for in situ conservation. Alternatively, stock enhancement practices should be taken, using offspring from wild spawners for artificial breeding programs. The relevant authorities should advise the reduction or cessation of fish harvests to allow population recovery. Routine genetic monitoring of remaining populations is highly recommended to assist with conservation management of the natural gene pool. Further genetic study involving large numbers of whisker sheatfish populations including both the Mekong River and the Chao Phraya River basins is also required. The whisker sheatfish outside Nong-Han Lake might be considered as a viable alternative genetic resource providing additional genetic diversity when Nong-Han whisker sheatfish are no longer self-sustainable. The conservation and management of the whisker sheatfish population should be conducted at the country scale, within which it might have the potential to become an important aquaculture species. It is therefore important to obtain data about catches for the management and conservation of fish stocks in Nong-Han Lake.

\section{ACKNOWLEDGMENTS}

Research supported by the Higher Education Research Promotion and National Research University Project of Thailand, Office of the Higher Education Commission, a grant from the Office of the Higher Education Commission (\#CHE490140), and the Kasetsart University Research and Development Institute (2007-2008). The authors thank Professor Uthairat Na-Nakorn and Associate Professor Dr Surin Peyachoknagul for technical suggestions. We also thank Mr Pramook Rukaewma, Sakon Nakhon Inland Fisheries Research and Development Center and Mr Sittichai Hatachote for sample collection.

\section{Supplementary material}

\section{REFERENCES}

Beaumont MA (2004). MSVAR 1.3 Update. Available at [http://www.maths.bris.ac.uk/ mamab/stuff]. Accessed June 8, 
2010.

Beerli P (2008). MIGRATE-n A Maximum Likelihood Program to Estimate Gene Flow Using the Coalescent. Available at [http://popgen.sc.fsu.edu/Migrate/Migrate-n.html]. Accessed December 17, 2010.

Bunt CM (2001). Fishway entrance modifications enhance fish attraction. Fish. Manag. Ecol. 8: 95-105.

Crow JF and Kimura M (1970). An Introduction to Population Genetics Theory. Harper and Row, New York.

Daungsawat S, Srichareontham B, Keawcharoon P and Aeamsap M (2003). Ecology and Fish Community in Nong Han Swamp, Sakon Nakhon Province. Technical Paper no. 6. Technical Coordination and Administration Group. Department of Fisheries.

De Woody JA and Avise JC (2000). Microsatellite variation in marine, freshwater and anadromous fishes compared with other animals. J. Fish Biol. 56: 461-473.

Di Rienzo A, Peterson AC, Garza JC, Valdes AM, et al. (1994). Mutational processes of simple-sequence repeat loci in human populations. Proc. Natl. Acad. Sci. U. S. A. 91: 3166-3170.

Ellegren H (2004). Microsatellites: simple sequences with complex evolution. Nat. Rev. Genet. 5: 435-445.

Foulley JL and Ollivier L (2006). Estimating allelic richness and its diversity. Livest. Sci. 101: 150-158.

Frankham R (1995). Conservation genetics. Annu. Rev. Genet. 29: 305-327.

Franklin IR (1980). Evolutionary Change in Small Populations. In: Conservation Biology: An Evolutionary-Ecological Perspective (Soul ME and Wilcox BA, eds.). Sinauer, Sunderland, 135-150.

Garza JC and Williamson EG (2001). Detection of reduction in population size using data from microsatellite loci. Mol. Ecol. 10: 305-318.

Goudet J (2001). FSTAT, A Program to Estimate and Test Gene Diversities and Fixation Indices (Version 2.9.3). Available at [http://www2.unil.ch/popgen/softwares/fstat.htm]. Accessed October 23, 2010.

Hanfling B and Weetman D (2006). Concordant genetic estimators of migration reveal anthropogenically enhanced source-sink population structure in the river sculpin, Cottus gobio. Genetics 173: 1487-1501.

Hill WG (1981). Estimation of effective population-size from data on linkage disequilibrium. Genet. Res. 38: 209-216.

Hogan ZS and May BP (2002). Twenty-seven new microsatellites for the migratory Asian catfish family Pangasiidae. Mol. Ecol. Notes 2: 38-41.

Holm S (1979). A simple sequentially rejective multiple test procedure. Scand. J. Stat. 6: 65-70.

Hundertmark KJ and Van Daele LJ (2010). Founder effect and bottleneck signatures in an introduced, insular population of elk. Conserv. Genet. 11: 139-147.

Jintanugool J and Round PD (2011). Nong Han. Available at [http://www.ramsar.wetlands.org/Portals/15/Thailand.pdf]. Accessed December 8, 2010.

Luikart G, Sherwin WB, Steele BM and Allendorf FW (1998a). Usefulness of molecular markers for detecting population bottlenecks via monitoring genetic change. Mol. Ecol. 7: 963-974.

Luikart G, Allendorf FW, Cornuet JM and Sherwin WB (1998b). Distortion of allele frequency distributions provides a test for recent population bottlenecks. J. Hered. 89: 238-247.

Na-Nakorn U and Moeikum T (2009). Genetic diversity of domesticated stocks of striped catfish, Pangasianodon hypophthalmus (Sauvage 1878), in Thailand: Relevance to broodstock management regimes. Aquaculture 297: 70-77.

Na-Nakorn U, Kamonrat W and Ngamsiri T (2004). Genetic diversity of walking catfish, Clarias macrocephalus, in Thailand and evidence of genetic introgression from introduced farmed C. gariepinus genome. Aquaculture 240: 145-163.

Na-Nakorn U, SriPhairoj K, Sukmanomon S and Poompuang S (2006). Polymorphic microsatellite primers developed from DNA of the endangered Mekong giant catfish, Pangasianodon gigas (Chevey) and cross-species amplification in three species of Pangasius. Mol. Ecol. Notes 6: 1174-1176.

Ngamsiri T, Ohashi YN, Sukmanomon S and Nakajima M (2006). Characterization of microsatellite DNA markers in a critically endangered species, Mekong giant catfish, Pangasianodon gigas. Mol. Ecol. Notes 6: 313-315.

Ngoichansri S, Nitsupap R and Sutti-arj S (2002). Efficiency and Selectivity of Gillnets in Nong Han, Sakon Nakhon Province. Available at [http://www.fisheries.go.th/if-SAKHON/ducument/net-SAKHON.doc]. Accessed December $3,2010$.

O’Connell M and Wright JM (1997). Microsatellite DNA in fishes. Rev. Fish Biol. Fish. 7: 331-363.

Parra-Bracamonte GM, Sifuentes-Rincón AM, De la Rosa-Reyna XF and Arellano-Vera W (2011). Inbreeding evidence in a traditional channel catfish (Ictalurus punctatus) hatchery in Mexico. J. Biotechnol. 14: 11.

Peel D, Ovenden JR and Peel SL (2004). NeEstimator: Software for Estimating Effective Population Size, Version 1.3. Queensland Government, Department of Primary Industries and Fisheries, Brisbane.

Phongkaew P, Hongtrakul V, Sangduen N and Thongpan A (2011). Isolation and characterization of eight novel microsatellite loci in whisker sheatfish (Micronema bleekeri Gunther, 1864). Conserv. Genet. Resour. 3: 425-427.

Piry SG, Luikart G and Cornuet JM (1999). Bottleneck: a computer program for detecting recent reductions in the effective 
population size using allele frequency data. J. Hered. 90: 502-503.

Quan YC, Sun XW and Liang LQ (2006). Genetic polymorphism of microsatellite dna in two populations of northern sheatfish (Silurus soldatovi). Yi Chuan Xue Bao 33: 908-916.

Rainboth WJ (1996). Fishes of the Cambodian Mekong. FAO species identification field guide for fishery purposes. FAO, Rome.

Raymond M and Rousset F (1995). GENEPOP: population genetics software for exact tests and ecumenicism. J. Hered. 86: 248-249.

So N, Maes GE and Volckaert FA (2006). High genetic diversity in cryptic populations of the migratory sutchi catfish Pangasianodon hypophthalmus in the Mekong River. Heredity 96: 166-174.

Tallmon DA, Koyuk A, Luikart G and Beaumont MA (2008). COMPUTER PROGRAMS: onesamp: a program to estimate effective population size using approximate Bayesian computation. Mol. Ecol. Resour. 8: 299-301.

van Oosterhout C, Hutchinson WF, Wills DPM and Shipley P (2004). Micro-Checker: software for identifying and correcting genotyping error in microsatellite data. Mol. Ecol. Notes 4: 535-538.

Weir BS and Cockerham CC (1984). Estimating F-statistics for the analysis of population structure. Evolution 38: 13581370.

Wilson GA and Rannala B (2003). Bayesian inference of recent migration rates using multilocus genotypes. Genetics 163: 1177-1191.

Yeh FC and Yang R (1999). POPGENE Version 1.31. Microsoft Window-Based Freeware for Population Genetic Analysis. University of Alberta/CIFOR, Edmonton. 